\title{
Variáveis geomorfométricas locais e sua relação com a vegetação da região do interflúvio Madeira-Purus (AM-RO)
}

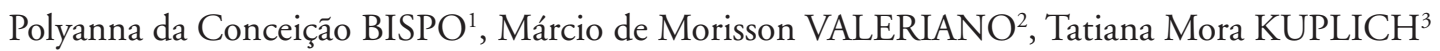

\begin{abstract}
RESUMO
O presente trabalho teve como objetivo avaliar o potencial das variáveis geomorfométricas extraídas de dados SRTM (Shuttle Radar Topographic Mission) para identificação de tipos vegetacionais da região do interflúvio Madeira-Purus. As variáveis geomorfométricas (elevação, declividade, orientação de vertente, curvatura vertical e curvatura horizontal) foram confrontadas com o mapa de vegetação do projeto RADAMBRASIL através de análises de histogramas e análises discriminantes. Tais análises indicaram os grupos de classes vegetacionais que podem ser separados mais facilmente em contraste com outros grupos que ocorrem sob as mesmas condiçôes topográficas. As variáveis de relevo mais importantes na distinção entre os tipos vegetacionais foram: a elevação, a declividade e a orientação de vertentes. Apesar dos dados geomorfométricos mostrarem potencial indicativo das classes de vegetação, as análises resultaram em discriminação em um nível aquém do detalhamento temático máximo apresentado pelos dados RADAM. Tal desempenho pode ser explicado pela incompatibilidade das escalas de variação exibidas entre os dados geomorfométricos em relação ao tamanho das unidades de mapeamento da vegetação, além da co-ocorrência de classes de respostas distintas ao relevo sob uma mesma associação de classes sob as mesmas classes na legenda. Com base nas análises discriminantes das variáveis geomorfométricas, foi possível o mapeamento da vegetação experimentalmente até o nível de subfisionomias.
\end{abstract}

PALAVRAS-CHAVE: Topografia, Vegetação, Amazônia, SRTM, Interflúvio Madeira-Purus

\section{Relation of local geomorphometric variables with the vegetation of the Madeira-Purus interfluve (AM/RO)}

\section{ABSTRACT}

The objective of this work was to assess the potential of geomorphometric variables, derived from SRTM (Shuttle Radar Topographic Mission) data, to help identify vegetation types in the Amazonian Madeira-Purus interfluvio region. A RADAMBRASIL project vegetation map was used as a reference and the geomorphometric variables (elevation, slope, aspect and profile and plan curvatures) were compared to the mapped units. Analyses indicated vegetation types easily discriminated, depending on the topographic position. The variables of elevation, slope and aspect were the most important for their high discrimination power of the vegetation types. Although geomorphometric data are recognized as having strong potential for characterizing vegetation, this was not shown in the results, due to the mismatching of variability scales between the two sources of data; large units tend to exhibit similar distribution patterns of geomorphometry, and comprise classes with different responses for geomorphometric constraints. Discriminant analyses of geomorphometric variables permitted vegetation mapping up to the sub-physiognomy levels.

KEYwORDS: Topography, Vegetation, Brazilian Amazonia, SRTM, Madeira-Purus interfluve

\footnotetext{
1 Instituto Nacional de Pesquisas Espaciais - INPE. Divisão de Sensoriamento Remoto. Caixa Postal 515 - CEP12245-970 - São José dos Campos, SP. Tel: (12) 3945-6732. e-mail: polyanna@ltid.inpe.br

2 Instituto Nacional de Pesquisas Espaciais - INPE. Divisão de Sensoriamento Remoto. Caixa Postal 515 - CEP12245-970 - São José dos Campos, SP. Tel: (12) 3945-6424. e-mail:valerian@ltid.inpe.br

${ }^{3}$ Instituto Nacional de Pesquisas Espaciais - INPE, Centro Regional Sul. Av. Roraima 1000, Camobi. CEP 97105-970 - Santa Maria, RS. Tel: (55) 3301-2307.

e-mail:tmk@ltid.inpe.br
} 


\section{INTRODUÇÃO}

Imagens de sensoriamento remoto têm sido utilizadas como base para os mapeamentos da vegetação da Amazônia em diferentes escalas. Dados de sensores ópticos fornecem informaçôes sobre o dossel vegetal que, com apoio de campo, são usados em mapeamentos diversos (Lucas et al., 2000; Espírito-Santo et al., 2005; Lu 2005). Evidentemente, estes dados têm sua capacidade limitada à medida que determinadas formações vegetais possuem respostas espectrais semelhantes.

Um dos principais projetos que visou o mapeamento da cobertura vegetal brasileira, em especial da Amazônia, foi o RADAMBRASIL. A variedade de atributos usados no sistema de classificação refletiu a variabilidade estrutural dos tipos de vegetação. As informaçôes geradas pelo projeto também confirmaram a importância da topografia na caracterização da paisagem local e regional, já que é um dos fatores determinantes do estabelecimento, distribuição e diversidade de espécies vegetais. Os mapas do RADAMBRASIL foram baseados nas informaçóes presentes em imagens de radar aerotransportado, sobre as quais a visualização dos padrōes de drenagem e a diferenciação entre áreas de várzea e terra firme são facilitadas graças à geometria de aquisição e iluminação do sistema sensor.

Estudos envolvendo o relevo e a vegetação são de grande importância para o entendimento da dinâmica e da formação da Floresta Amazônica. Nesta, o relevo é usado como a base para uma classificação primária, que define a Amazônia como primordialmente coberta por formaçóes florestais (80\% de acordo com MMA 2007) de terra firme e de várzea (ou inundáveis) (Pires e Prance 1985). Na classificação de vegetação proposta por Veloso et al (1991) e utilizada no RADAMBRASIL, a caracterização do relevo é parte integrante da especificação das formaçōes vegetais, como aluviais, de terras baixas, submontana, montana etc.

Outros estudos mostram que a heterogeneidade das condições do solo na Amazônia é frequentemente ligada à topografia e exerce uma notável influência sobre a composição, a estrutura e os padrões de diversidade da floresta (Lescure \& Boulet, 1985; Pelissier et al., 2001). A topografia da Amazônia Central é fortemente correlacionada com a textura do solo (Chaveul, et al., 1987), e estes fatores são os maiores condicionantes da distribuição de espécies vegetais e da estrutura de suas comunidades, em escalas local e regional (Sollins, 1988; Lieberman et al., 1985; Kubota et al., 2004). A comunidade de palmeiras, por exemplo, se distribui em três zonas de acordo com as condiçōes hidromórficas do solo: solos bem drenados (platô, topo, vertente), solos pobremente drenados (zona de transição) e solos sazonalmente inundados (igarapés). Desse modo, foi verificado que a distribuição de diferentes espécies de palmeiras está fortemente relacionada ao tipo de solo, cuja distribuição depende da situação topográfica local (Kahn \& Castro, 1985). Tal condicionamento não se restringe à distribuição de tipos vegetacionais: cerca de 30\% das variaçôes espaciais nas estimativas de biomassa de árvores estão relacionadas às características do solo e à topografia (Laurence et al., 1999; Castilho et al. 2006). Adicionalmente, nas florestas de várzea a topografia pode definir a riqueza e distribuição de espécies vegetais ao longo do gradiente de inundação e sedimentação (Wittman et al., 2004).

Embora se reconheçam os dados topográficos com importante fonte de informaçôes para subsidiar o mapeamento da vegetação (Passos, 1981; Dargie, 1984; Dargie, 1987; Kirkby et al., 1990; Florinsky \& Kuryakova, 1996; VelázquezRosas et al., 2002), o estabelecimento de metodologias com este aporte ainda requer o desenvolvimento de estudos específicos (Kellndorfer et al., 2004). Tal condição pode ser explicada por uma histórica ausência de levantamentos topográficos detalhados, pela qual grande parte do território nacional permanece com mapeamentos em escalas inadequadas para várias aplicações. Neste contexto, a utilização de bases topográficas obtidas por sensores orbitais pode viabilizar esses estudos.

A missão SRTM (Shuttle Radar Topographic Mission), ocorrida em 2000, possibilitou a coleta de dados altimétricos para praticamente toda a superfície terrestre. A existência desses dados em cobertura nacional permite que se avalie e se desenvolva seu potencial para o mapeamento da vegetação de forma relativamente padronizada em diferentes ambientes.

Os dados SRTM mostraram que são passíveis de derivação em variáveis geomorfométricas, para expressão das diferentes características do relevo, o que resulta num conjunto de dados em complemento à altimetria (Valeriano, 2005). Cada variável condiciona a vegetação através de diferentes aspectos da paisagem (temperatura, exposição solar e hidrologia, por exemplo), além do controle direto sobre o transporte e o acúmulo de nutrientes, estruturas de propagação, biomassa e substâncias vegetais, que afetam sua distribuição.

O presente trabalho tem como objetivo avaliar o uso isolado das variáveis geomorfométricas locais extraídas de modelos digitais de elevação SRTM para identificação de tipos vegetacionais de uma área no sul do interflúvio Madeira-Purus. Neste objetivo, este estudo busca selecionar as variáveis geomorfométricas que melhor caracterizam os tipos de vegetação e, reciprocamente, identificar as condições geomorfométricas para ocorrência das diferentes classes observadas. 


\section{MATERIAL E MÉTODOS}

ÁREA DE ESTUDO

Foi selecionada uma área com diversidade topográfica e vegetacional que dispusesse de um mapeamento de vegetação publicado. Desse modo, área selecionada faz parte da folha ao milionésimo SB 20 Purus, descrita no volume 17 do Projeto RADAMBRASIL (Figura 1). Desta, foram selecionadas duas quadrículas 1:250.000 ( $1^{\circ}$ por $\left.1,5^{\circ}\right)$, folhas SB 20Y-C (Labrea) e SB 20-Y-D (Humaitá). Apesar da variação altimétrica não ser alta, esta área foi selecionada por apresentar grande variedade de formaçôes vegetais, incluindo áreas de savana. Nesta região também estão presentes a floresta densa, floresta aberta e formações pioneiras (nas várzeas), descritas abaixo. A área faz parte do interflúvio dos rios Madeira e Purus e tem como importantes cursos d'água os rios Purus, Ituxi, Mucuim e Ipixuna (RADAMBRASIL 1978). A maior parte das folhas é situada no estado do Amazonas, com pequena parte em Rondônia. Os centros urbanos de Lábrea e Humaitá estão localizados na área de estudo.

As principais formações vegetais presentes na área de estudo são descritas resumidamente abaixo, com informaçôes do Projeto RADAMBRASIL (1978). As classes de floresta ombrófila densa e aberta serão referidas no restante do texto (com exceção da legenda da Figura 1) apenas como floresta densa e floresta aberta, com informações adicionais quando necessárias.

\section{FLORESTA OMBRÓFILA DENSA DAS TERRAS BAIXAS}

Formação que apresenta agrupamentos de árvores emergentes nas elevações mais pronunciadas dos interflúvios, como o angelim-da-mata (Hymenolobium petraeum), angelimpedra (Dinizia excelsa), tauari (Couratari spp.), castanhado-pará (Bertholletia excelsa) entre outras. É significativa a presença de palmeiras que competem por luz no estrato arbóreo superior: babaçu (Orbygnia spp.), patauá (Oenocarpus bataua), açaí (Euterpe spp.), ocorrendo preferencialmente nos locais mais úmidos.

\section{FLORESTA OMBRÓFILA DENSA ALUVIAL}

Formação característica das áreas inundáveis pelas cheias sazonais, ecologicamente adaptadas às intensas variaçôes do nível da água e beneficiada pela renovação regular do solo decorrente das enchentes periódicas. A sumaúma (Ceiba pentandra), provida de enormes raízes tabulares, é a representante mais expressiva neste grupo de formação. Apresenta também muitas palmeiras no estrato intermediário.

\section{FLORESTA OMBRÓFILA ABERTA DAS TERRAS BAIXAS}

Formação característica por feição mista de palmeiras e árvores latifoliadas, sempre verdes e bem espaçadas, de altura
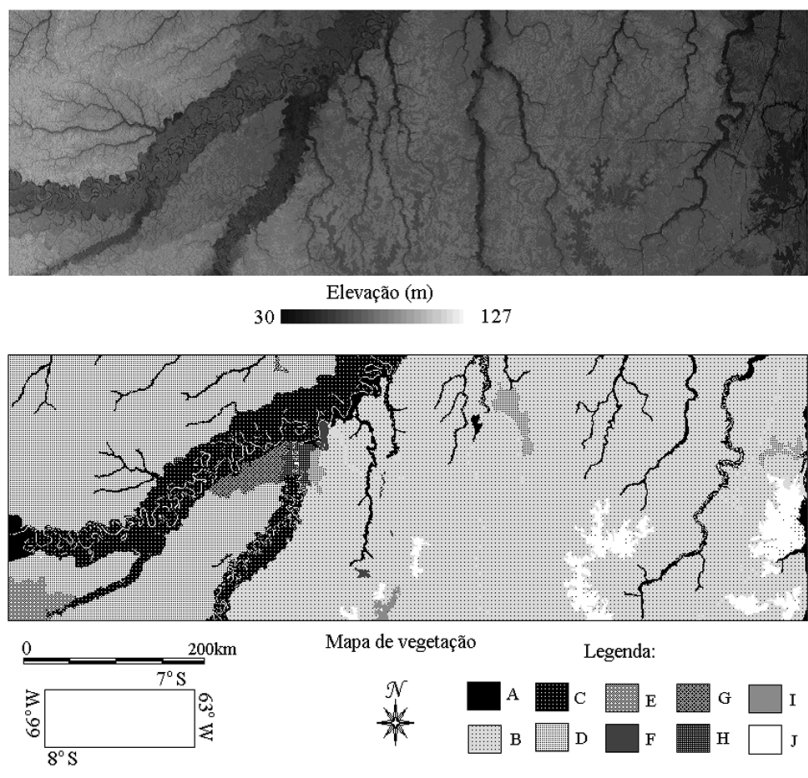

Figura 1 - Modelo digital de elevação (acima) e Mapa de vegetação da área de estudo (abaixo) com as classes A (Floresta Ombrófila Aberta Aluvial com palmeiras), B (Floresta Ombrófila Aberta Terras Baixas com palmeiras), C (Floresta Ombrófila Densa Aluvial Dossel emergente), D (Floresta Ombrófila Densa Terras Baixas Dossel emergente), E (Floresta Ombrófila Densa Terras Baixas Dossel uniforme), F (Formações Pioneiras com influência fluvial e/ ou lacustre - arbustiva), G (Formações Pioneiras com influência fluvial e/ou lacustre - arbustiva com palmeiras), H (Formações Pioneiras com influência fluvial e/ou lacustre - herbácea), I ( Savana Gramíneo-Lenhosa sem florestade-galeria) e J (Savana Parque sem floresta-de-galeria).

irregular (entre 15 e $25 \mathrm{~m}$ ), com grupamentos de babaçu e patauá, principalmente nos interfúvios do Terciário. Nos vales de fundo chato, de encharcamento constante ocorre concentração de buriti (Mauritia flexuosa), em povoamentos puros.

\section{FLORESTA OMBRÓFILA ABERTA ALUVIAL}

É uma formação arbórea com palmeiras que ocupa principalmente as planícies e terraços dos rios. Característica de regiōes inundáveis pelas cheias sazonais, ecologicamente adaptados às intensas variaçõos do nível da água, beneficiando da renovação do solo decorrente das enchentes periódicas.

\section{SAVANA GRAMÍNEO-LENHOSA}

Prevalecem nesta fisionomia os gramados entremeados por plantas lenhosas raquíticas, que ocupam extensas áreas e que, aos poucos, quando manejadas através do fogo ou pastoreio, vão sendo substituídas por espécies que apresentam colmos subterrâneos, portanto, mais resistentes ao pisoteio do gado ao fogo. 


\section{SAVANA PARQUE}

Formação com características fisionômicas mais típicas, com arbustos esparsos de no máximo $7 \mathrm{~m}$ de altura, em meio a estrato rasteiro denso, dominando por gramíneas.

\section{FORMAÇÕES PIONEIRAS}

São formações em fase de sucessão (hidrossere), encontradas em ambientes de solos sazonais, que se situam ao longo dos rios e em locais deprimidos dos interflúvios tabulares do Terciário ou dispersas no interior das florestas Densa e/ou Aberta. Estas formaçôes ocupam áreas de influência aluvial (planícies e terraços) e de influência pluvial (depressōes nos interflúvios).

\section{DADOS VEGETACIONAIS E TOPOGRÁFICOS}

$\mathrm{O}$ dado de vegetação corresponde ao mapa fisionômicoecológico das Folhas SB 20-Y-C e SB 20-Y-D, em formato vetorial, em escala 1:250.000 do Projeto RADAMBRASIL (1978), digitalizados recentemente pela equipe do SIPAM (Sistema de Proteção da Amazônia).

Os dados topográficos provieram do banco de dados geomorfométricos TOPODATA (Valeriano, 2005), preparados conforme os procedimentos estabelecidos nesta iniciativa. Os dados SRTM das áreas selecionadas foram refinados de 3" para 1" com krigagem e em seguida derivados em variáveis geomorfométricas através de diferentes operações de vizinhança (Valeriano et al., 2006). Foram derivadas as seguintes variáveis: $(G)$ declividade, $(A)$ orientação de vertentes, $\left(k_{v}\right)$ curvatura vertical e $\left(k_{b}\right)$ curvatura horizontal, além da própria $(h)$ elevação, para área de estudo.

\section{AMOSTRAGEM E ANÁLISE DOS DADOS}

Após a seleção do mapa de vegetação foi feita a migração e a compatiblização destes dados com os dados geomorfométricos. Foi feita uma amostragem das variáveis por classe vegetacional em esquema aleatório estratificado. Foram definidas diferentes densidades de amostragem para que a cada classe fossem escolhidos aproximadamente 50 pontos. Os dados amostrados foram pareados em planilhas de acordo com sua posição geográfica e o conteúdo destas planilhas submetido às análises estatísticas.

Os planos de informação armazenados foram editados na forma de mapas uniformizados para uma visualização conjunta dos dados. Foram elaborados histogramas das variáveis geomorfométricas dentro da área de cada classe de vegetação, buscando identificar grupos de classes de comportamento semelhantes e variáveis de maior poder indicativo dos mesmos.

A separação estatística das classes de vegetação com base nas variáveis geomorfométricas foi verificada através de análises discriminantes (Manly, 1994). A aplicação das análises foi feita após agrupar classes de vegetação com estruturas semelhantes, que no mapa de referência estavam muito particularizadas. Estas análises foram aplicadas também dentro dos grupos vegetacionais formados por mais de duas subfisionomias, com o intuito de avaliar o uso das variáveis geomorfométricas como indicadores de classes no nível das subfisionomias vegetais. Para melhorar a linearidade dos dados, estes foram logaritmizados e posteriormente padronizados.

As novas classes de vegetação, formadas a partir do reagrupamento dos dados de vegetação originais correspondem: à Floresta Aberta (Floresta Aberta Aluvial com palmeiras, Floresta Aberta Terras Baixas com palmeiras), às Formaçôes Pioneiras (classes agrupadas: Formações Pioneiras com influência fluvial e/ou lacustre - arbustiva, Formaçôes Pioneiras com influência fluvial e/ou lacustre - arbustiva com palmeiras, Formações Pioneiras com influência fluvial e/ou lacustre - herbácea), à Floresta Densa (classes agrupadas: Floresta Densa Aluvial Dossel emergente, Floresta Densa Terras Baixas Dossel emergente, Floresta Densa Terras Baixas Dossel uniforme) e à Savana (Savana Gramíneo-Lenhosa sem floresta-de-galeria, Savana Parque sem floresta-de-galeria ).

Com vistas a uma avaliação do potencial de aplicação dos dados geomorfométricos no mapeamento da vegetação, foram realizados processamentos que tiveram como base as observações gerais e os resultados das análises estatísticas.

As análises discriminantes aplicadas sobre as classes vegetacionais reagrupadas, assim como dentro dos grupos que incluíam mais de duas subfisionomias, indicaram as variáveis geomorfométricas de maior peso na separação dos grupos, bem como quais desses grupos melhor se separavam entre si. Os planos de informação das variáveis geomorfométricas foram operados com a equação da primeira função discriminante (na qual a maior parte da variação dos dados se concentrou), resultando em uma nova imagem, referente a esta função. Um mapa experimental de vegetaçáo foi gerado a partir de classificaçôes por Fatiamentos, aplicadas sobre essa imagem. O mapa gerado foi editado em comparação com os dados de vegetação agrupados sob as novas classes, em função das similaridades observadas.

\section{RESULTADOS E DISCUSSÃO}

\section{CARACTERIZAÇÃO DA VEGETAÇÃO QUANTO AS VARIÁVEIS GEOMORFOMÉTRICAS}

$\mathrm{Na}$ apreciação inicial dos dados, puderam ser observadas as faixas de amplitude numérica dos dados topográficos (Figura 1 e 2), indicando a diferenciação geomorfométrica dentro de cada variável. Os dados de curvaturas se apresentaram naturalmente homogêneos quando observada a área por inteiro, devido ao caráter fortemente localizado dessas variáveis em relação ao tamanho da área. Da apreciação geral dos mapas, foi observado 
que nos dados topográficos predominam variaçôes de alta frequiência, se comparados à distribuição espacial das classes de vegetação. Tal característica se mostra clara nos detalhes das derivaçôes geomorfométricas (da Figura 2), em que se percebe a totalidade de variação dentro de um curto espaço. Os dados de elevação e de declividade, em menor grau, mostraram ligeira tendência de regionalização. Comparando os mapas da Figuras 1, foi verificado que as classes A e C são caracterizadas por diferenças consistentes de elevação, correspondentes a grandes domínios altimétricos (patamares e planícies de inundação). As principais variaçōes dos valores de declividade, por sua vez, estão associadas a feições de drenagem ou às transições entre terra firme e as várzeas.

A distribuição numérica e a amplitude dos dados geomorfométricos puderam ser observadas em histogramas, na Figura 3, que mostram a distribuição das variáveis geomorfométricas dentro de cada classe de vegetação, em comparação com a área de estudo total. Verificando a área total, foi observado que altitude varia entre 30 e $127 \mathrm{~m}$, com distribuição bimodal com o maior pico em valores mais baixos de altimetria. A sua declividade máxima está em torno de 37\%, com uma relativa concentração da distribuição em torno de valores baixos. A homogeneidade de orientações de vertentes e a simetria da distribuição das curvaturas horizontal e vertical indicam o equilíbrio entre as condiçôes de terreno na totalidade desta área, o que está de acordo com as observaçôes feitas acerca destas variáveis quando integradas regionalmente (Valeriano 2003 e Valeriano \& Carvalho Júnior, 2003). Diferenças de distribuiçôes nestas variáveis são esperadas somente em observaçōes localizadas. Coerentemente, a heterogeneidade da distribuição de orientação de vertentes foi observada em classes de vegetação de menor expressão territorial.

Dado o tamanho das unidades de mapeamento fornecidas pelo RADAM, aliado às características das variáveis topográficas derivadas, o padrão de distribuição das variáveis foi, como regra, semelhante entre as diferentes classes. A despeito da incompatibilidade de escalas de variação, algumas diferenças puderam ser observadas nos histogramas. As ocasionais diferenças de distribuição entre as classes de vegetação são indicadores de sua adaptação preferencial a determinadas condiçōes topográficas.

A Floresta Aberta Aluvial com palmeiras (A) ocorre com maior freqüência em regiōes de altitudes em torno 68 e de $86 \mathrm{~m}$. A distribuição da declividade mostra que este tipo de formação se mostra pouco tolerante a declividades altas, se concentrando em áreas com declividades próximas a 3\% (plano), apresentando comportamento semelhante às demais classes de vegetação.

A Floresta Aberta Terras Baixas com palmeiras (B) ocorre com maior freqüência em regiōes de altitudes em torno de $88 \mathrm{~m}$. A Floresta Densa Aluvial Dossel emergente (C) possui distribuição altimétrica em torno $68 \mathrm{~m}$. Ao passo que Floresta Densa Terras Baixas Dossel emergente (D) apresenta dois estratos de distribuição, o estrato mais alto em torno de $107 \mathrm{~m}$ e o mais baixo em torno de $88 \mathrm{~m}$.

A Floresta Densa Terras Baixas Dossel uniforme (E) possui altitude em torno de $115 \mathrm{~m}$, Formações Pioneiras com influência fluvial e/ou lacustre - arbustiva (F) em torno de 58 m, Formações Pioneiras com influência fluvial e/ou

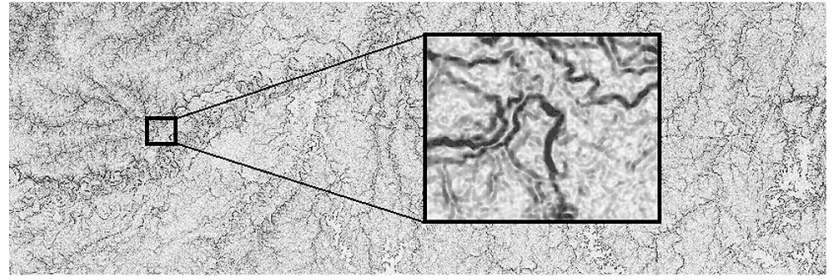

Declividade (\%):

$0 \quad 37$

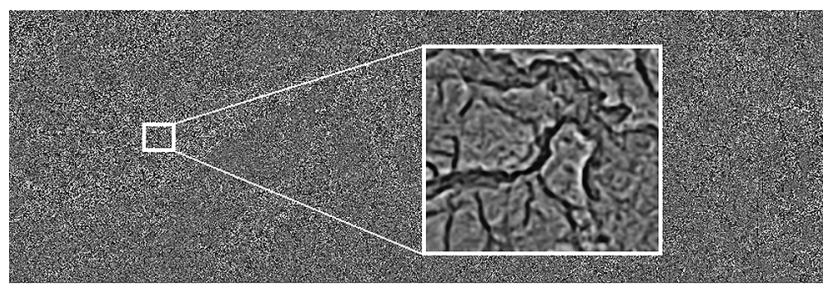

Curvatura vertical $(\% / \mathrm{m})$ :

$-0.083 \square+0.083$

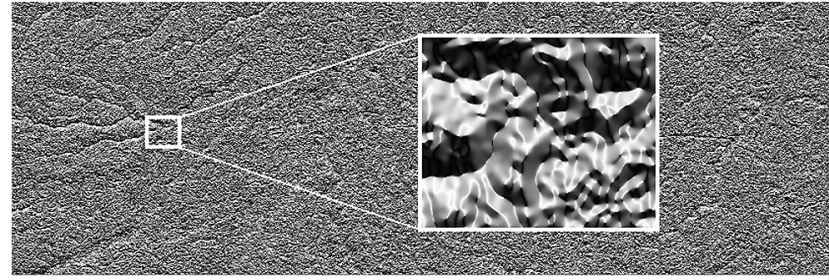

Orientação de vertente $\left(^{\circ}\right)$ :

$0 \quad 360$

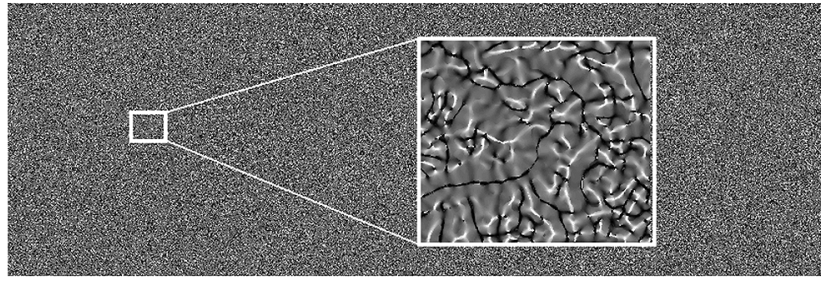

Curvatura horizontal $(\% / \mathrm{m})$

$-2.5 \square+2.5$

Figura 2 - Mapas das variáveis geomorfométricas locais derivadas dos dados SRTM. Escala e posicionamento iguais aos mapas de Figura 1. 
lacustre - arbustiva com palmeiras (G) em torno de $83 \mathrm{~m}$, Formaçôes Pioneiras com influência fluvial e/ou lacustre herbácea em torno de 56 m, Savana Gramíneo-Lenhosa sem floresta-de-galeria (I) em torno de $80 \mathrm{~m}$ e Savana Parque sem floresta-de-galeria (J) em torno de 56 a $72 \mathrm{~m}$.

Da observação conjunta dos histogramas de todas as classes, foi verificado que as preferências ecofisiológicas das diferentes classes de vegetação, quando expressas, estão representadas pela concentração de freqüência das variáveis geomorfométricas. Entretanto, mesmo entre as classes de maior contraste geomorfométrico, as distribuiçōes apresentam amplitudes sobrepostas, com raros casos de condições excludentes. Nas distribuições de curvaturas, conforme se relata no desenvolvimento de seu cálculo (Valeriano, 2003; Valeriano \& Carvalho Júnior, 2003), regiōes geomorfológicas distintas diferem pelo grau de dispersão (variância) em torno dos valores nulos. Porém, tal característica pode estar associada ao tamanho das áreas em que estes valores são computados (Doornkamp \& King, 1971), uma vez que tal dispersão se mostrou condicionada a área relativa de cada classe.

\section{EFEITO DO RELEVO SOBRE AS FISIONOMIAS VEGETAIS E SOBRE AS SUAS SUBFISIONOMIAS}

Análises estatísticas foram empregadas diante do agrupamento de classes vegetacionais em função da semelhança

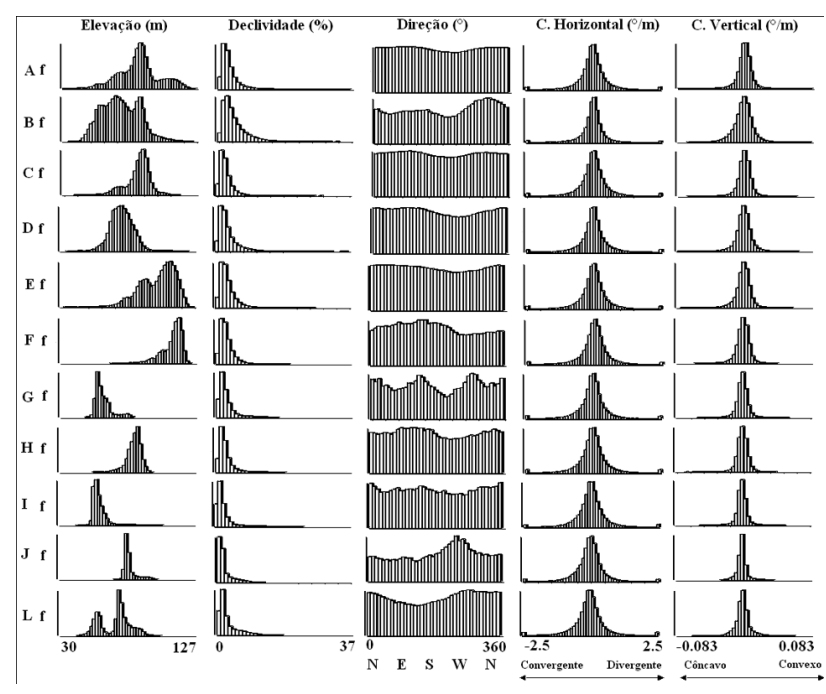

Figura 3 - Distribuição de freqüência (f) das variáveis topográficas nas classes de vegetação em totalidade e de suas classes de vegetação: A (Floresta Aberta Aluvial com palmeiras), B (Floresta Aberta Terras Baixas com palmeiras), C (Floresta Densa Aluvial Dossel emergente), D (Floresta Densa Terras Baixas Dossel emergente), E (Floresta Densa Terras Baixas Dossel uniforme), F (Formações Pioneiras com influência fluvial e/ou lacustre - arbustiva), G (Formações Pioneiras com influência fluvial e/ou lacustre - arbustiva com palmeiras), H (Formações Pioneiras com influência fluvial e/ou lacustre herbácea), I (Savana Gramíneo-Lenhosa sem floresta-de-galeria) e J (Savana Parque sem floresta-de-galeria). estruturais de sua vegetação. Assim foram gerados novos mapas de vegetação referência.

A análise discriminante foi significativa na separação dos grupos vegetacionais com base nas variáveis geomorfométricas (Wilks' Lambda geral: 0,59817 F $(9,1199)=31,346 \mathrm{p}<0$. 0000). As maiores significâncias na construção do modelo foram as variáveis elevação $(b)$, declividade $(G)$ e a curvatura vertical $\left(k_{\mathrm{v}}\right)$ com Wilks' lambdas de 0,8978, 0,6551 e 0,6041, respectivamente.

A elevação que corresponde à altitude do terreno está relacionada à distribuição altitudinal do solo e do clima, condicionando diferentes padrões vegetacionais na paisagem. A declividade por sua vez possui ação direta sobre o equilíbrio entre a infiltração de água no solo e escoamento superficial, além de controlar a intensidade dos fluxos de matéria e insolação (Schmidt et al., 2003). Esse conjunto de fatores resulta na formação de ambientes com diferentes características físicas e biológicas, as quais permitem o estabelecimento de diferentes tipos de vegetação. Finalmente a curvatura vertical corresponde ao caráter côncavo/convexo do terreno e está relacionada aos processos de migração e acúmulo de água, minerais e materiais orgânicos no solo através da superfície, proporcionados pela gravidade (Schmidt et al., 2003).

A seleção destas variáveis como àquelas que mais discriminam a variação da vegetação são coerentes com as características da área em estudo. Nela há predominância de interflúvios tabulares do Terciário entre faixas de planície e de terraços do Quaternário, elaborados pelos rios Madeira, Purus e seus afluentes (RADAMBRASIL, 1978), portanto com grande variação no relevo, particularmente nas variáveis: elevação, declividade e curvatura vertical. As depressōes situadas sobre estes interflúvios, possuem em geral, as bordas mais altas o que facilita o acúmulo das águas pluviais. Esse grau de impedimento da drenagem aliado ao tipo de solo (variando de Podzol Hidromórfico a Laterita Hidromórfica, ou ainda Areia Quartzosa Hidromórfica) influirá na paisagem vegetacional.

A distância entre os centróides dos grupos no espaço discriminante (Distância de Mahalanobis) mostrou que os grupos mais distantes entre si foram: Floresta Densa e Formaçōes Pioneiras (3.769699) e as mais próximas foram Savana e Formaçōes Pioneiras (0.747576). Todas as distâncias foram significativas, indicando que as variáveis geomorfométricas foram capazes de discriminar a maioria dos tipos de vegetação. As variáveis topográficas explicaram apenas parte da variação, sendo fundamental a consideração de outros fatores ambientais que influenciam tal variação.

Este fato corrobora com estudos mais recentes desenvolvidos na regiáo amazônica (Wittman et al., 2004; Kubota et al., 2004; Castilho et al., 2006) que confirmam que fatores como clima e solo, ao lado da topografia são responsáveis 
pela variação e pela diversidade vegetacional existentes na Amazônia, sendo que, quando vistos isoladamente, cada um desses fatores explica apenas parte da variação da vegetação.

Quanto aos processamentos baseados nas análises discriminantes, a geração da imagem da primeira função discriminante da área permitiu a obtenção de uma classificação muito similar ao mapa referência.

As feições vegetacionais são observadas claramente (Figura 4) na função 1. Nela todas as classes são distinguidas facilmente, exceto a classe Formaçōes Pioneiras. Assim, o mapa obtido por Fatiamento a partir da função 1 mostrou resultado satisfatório, distinguindo a Floresta Densa, a Floresta Aberta e a Savana. Embora a primeira se mostre sutilmente subestimada e a última superestimada, ambas evidenciam claramente as tendências dos diferentes tipos de vegetação no terreno.

Dentro dos grupos Formaçôes Pioneiras e Floresta Densa, também foi feita análise discriminante para verificar se as variáveis topográficas são preditoras das diferenças existentes dentro destes grupos.

A análise discriminante referente às Formações Pioneiras foi significativa na separação dos grupos vegetacionais com base nas variáveis morfométricas (Wilks' Lambda geral: 0,2194 $\mathrm{F}(9,474)=45.619 \mathrm{p}<0,0000)$. Este tipo de vegetação em geral se situa nas depressões dos interflúvios tabulares e nas áreas de acumulação aluvial, especialmente ao longo do Rio Purus compreendendo uma faixa de transição em planície aluvial (RADAMBRASIL, 1978). As variáveis elevação (b), curvatura vertical $\left(k_{v}\right)$ e orientação de vertentes $(A)$ foram as
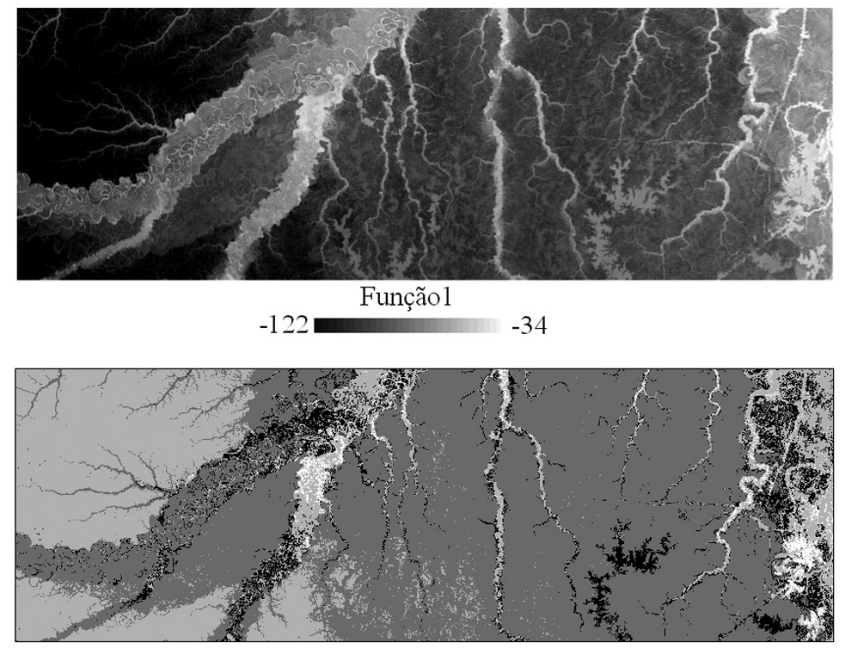

Mapa gerado a partir da Funçãol mais importantes na discriminação dos grupos, com Wilks' lambdas de 0.9883, 0.2035 e 0.2002 , respectivamente.

A distância entre os centróides (Distância de Mahalanobis) dos grupos no espaço discriminante permitiu a verificação que os grupos mais distantes entre si foram Formaçōes Pioneiras com influência fluvial e/ou lacustre - herbácea e Formações Pioneiras com influência fluvial e/ou lacustre - arbustiva com palmeiras (19.75363) e as mais próximas foram Formaçōes Pioneiras com influência fluvial e/ou lacustre - herbácea e Formaçôes Pioneiras com influência fluvial e/ou lacustre - arbustiva (0.16718). Entretanto as distâncias entre estas últimas não foram consideradas significativas.

Quanto ao processamento, foi observado que o resultado do Fatiamento das Formações Pioneiras foi quase idêntico ao do mapa de vegetação referência, exceto pela ausência de Formações Pioneiras com influência fluvial e/ou lacustre - arbustiva (Figura 5). Na Função 1 foi possível perceber claramente um indicativo da classe Formaçôes Pioneiras com influência fluvial e/ou lacustre - arbustiva com palmeiras, aparecendo em tom mais escuro nesta imagem. Para Floresta Densa os resultados encontrados também foram muito promissores.

A Floresta Densa apresentou uma análise discriminante significativa na separação dos grupos vegetacionais com base nas variáveis morfométricas (Wilks' Lambda geral: $0,2505 \mathrm{~F}$ $(6,292)=48,565 \mathrm{p}<0,0000)$. Este tipo de fisionomia reveste as mais variadas formas de relevo pertencentes a diferentes épocas geológicas (RADAMBRASIL, 1978). As variáveis mais

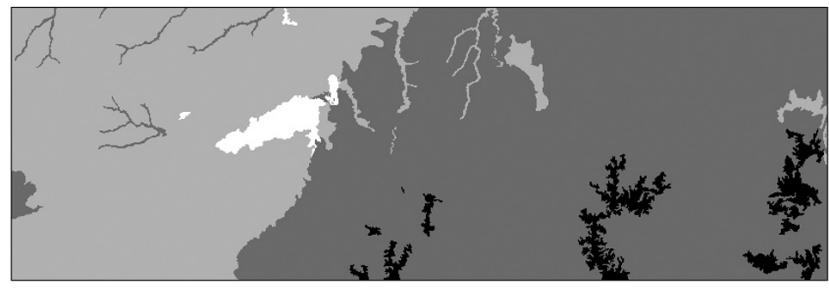

Referência: Mapa de vegetação - agrupado

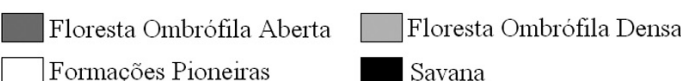
Formações Pioneiras $\quad$ Savana

Figura 4 - Imagens da Função discriminante 1, Classificação por Fatiamento da Função discriminante 1 sobre variáveis geomorfométricas e Mapa de vegetação com classes agrupadas: Floresta Aberta ( Floresta Aberta aluvial (A), Floresta Aberta de Terras Baixas com palmeiras (B)), Formações Pioneiras (Formações Pioneiras com influência fluvial e/ou lacustre - arbustiva (F), Formações Pioneiras com influência fluvial e/ou lacustre - arbustiva com palmeiras (G), Formações Pioneiras com influência fluvial e/ou lacustre - herbácea) (H)), Floresta Densa (Floresta Densa Aluvial Dossel emergente (C), Floresta Densa Terras Baixas Dossel emergente (D), Floresta Densa Terras Baixas Dossel uniforme (E)), Savana (Savana Gramíneo-Lenhosa (I) sem floresta-de-galeria, Savana Parque sem floresta-de-galeria (J)). 


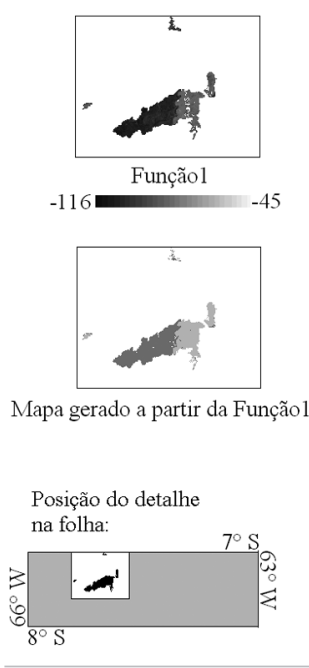

Figura 5 - Imagens da Função discriminante 1, Classificação por Fatiamento da Função discriminante 1 sobre variáveis geomorfométricas para as Formações Pioneiras e Mapa de vegetação como referência: Formações Pioneiras com influência fluvial e/ou lacustre - arbustiva, Formações Pioneiras com influência fluvial e/ou lacustre - arbustiva com palmeiras, Formações Pioneiras com influência fluvial e/ou lacustre - herbácea.

importantes na discriminação dos grupos foram a elevação $(b)$, curvatura vertical $\left(k_{\mathrm{v}}\right)$ e curvatura horizontal $\left(k_{\mathrm{h}}\right)$, com Wilks' lambdas de 0, 9159, 0, 2877 e 0, 2555, respectivamente.

Observando a distância entre os centróides (Distância de Mahalanobis) dos grupos no espaço discriminante foi verificado que os grupos mais distantes entre si foram Floresta Densa Aluvial Dossel emergente e Floresta Densa Terras Baixas Dossel uniforme (17.02336) e as mais próximos foram
Floresta Densa Terras Baixas Dossel emergente e Floresta Densa Terras Baixas Dossel uniforme (1. 427646).

A classe Floresta Densa com dossel emergente foi a que melhor se assemelhou ao mapa de vegetação, enquanto as demais classes mostraram bons resultados (Figura 6). Há de se considerar que a Floresta Densa das Terras Baixas com dossel emergente e a Floresta Densa das Terras Baixas com dossel uniforme mostraram certa diferenciação entre o mapa gerado a partir da Função discriminante 1 e o mapa de vegetação referência.

O desempenho das análises discriminantes atingido para subfisionomias foi superior àquele observado para a totalidade das classes, o que pode ser explicado pelas relaçōes de escala entre os dados topográficos e de vegetação. A maior particularização da análise tem dois efeitos favoráveis à separabilidade "geomorfométrica". Em primeiro lugar, as classes mais detalhadas têm menor expressão territorial, o que dá mais chance para a observação de variaçôes locais, como se observou ser o comportamento típico das derivaçôes geomorfométricas. Unidades de mapeamento de áreas menores tendem a apresentar distribuições mais concentradas das variáveis, conforme a condição localizada das mesmas. Em segundo, a própria particularização das classes traz mais uniformidade dentro dos grupos vegetacionais, o que pode revelar maior responsividade das mesmas em relação aos fatores do meio físico que influenciam sua distribuição. Em contraposição, unidades mais abrangentes tendem a agrupar formaçōes vegetais com distintas respostas a estas condiçôes, além de terem sua distribuição espalhada por áreas maiores e internamente heterogêneas. Como efeito, a distribuição das
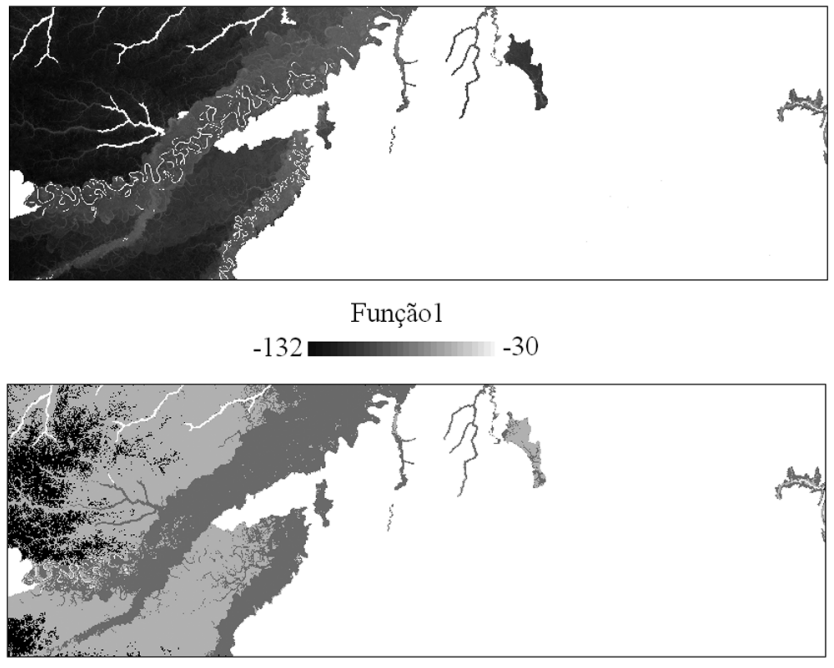

Mapa gerado a partir da Funçãol

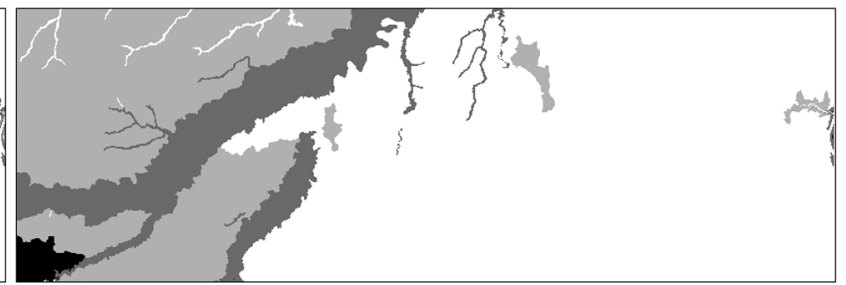

Referência:

Mapa de vegetação - Floresta ombrófila densa

Floresta ombrófila densa aluvial dossel emergente

Floresta ombrófila densa terras baixas dossel emergente

Floresta ombrófila densa terras baixas dossel uniforme

Figura 6 - Imagem da Função discriminante 1, Classificação por Fatiamento da Função discriminante 1 sobre variáveis geomorfométricas para a Floresta densa e Mapa de vegetação como referência:. Floresta Densa Aluvial Dossel emergente, Floresta Densa Terras Baixas Dossel emergente e Floresta Densa Terras Baixas Dossel uniforme. 
variáveis geomorfométricas se mostra homogênea entre estas unidades de mapeamento.

Tais aspectos indicam que a inserção dos dados SRTM em estudos de mapeamento da vegetaçáo está condicionada a uma adequação das escalas, para que relações reconhecidamente fundamentadas não sejam subestimadas. A não observância desse cuidado pode levar à conclusões equivocadas, comprometendo todo potencial de utilização dos dados SRTM. Para dados de vegetação como os usados no presente estudo, a análise do relevo deve seguir uma abordagem regional (não-local), para o que se recomendam identificação de domínios geomorfométricos, análises da drenagem, integração em microbacias e outras formas de caracterização do relevo em áreas, ao invés de pontos. Por outro lado, o potencial dos dados geomorfométricos SRTM em sua plena resolução espacial só poderá ser avaliado sob abordagens pontuais mediante estudo com dados de vegetação com detalhamento compatível.

\section{CONCLUSÕES}

O presente trabalho foi conduzido com o intuito de avaliar as variáveis geomorfométricas extraídas de modelos digitais de elevação do SRTM para subsidiar o mapeamento da vegetação da Amazônia. A partir dos resultados obtidos, foram assinaladas as seguintes conclusôes:

A escala de variação dos dados geomorfométricos derivados da altimetria SRTM mostra um grande detalhamento local, incompatível com o grau de generalização dos mapas de vegetação fornecidos pelo RADAM. De modo geral, as variáveis geomorfométricas derivadas mostraram distribuições indistintas quando se comparam todas as classes de vegetação mapeadas.

As classes de vegetação mapeadas foram controladas pela elevação, refletindo sua relação com os domínios altimétricos da área, como patamares e várzeas.

Embora os dados geomorfométricos tenham mostrado potencial indicativo das classes de vegetação, estas puderam ser identificadas em um nível aquém do detalhamento temático da maioria dos mapas em função da co-ocorrência de classes com semelhantes estruturas.

Os grupos que mais se separaram com base na geomorfometria foram as Formaçôes Pioneiras e Floresta Densa. Merece destaque a separação entre Formações Pioneiras com influência fluvial e/ou lacustre - arbustiva e Formaçôes Pioneiras lacustre - herbácea. Para fisionomia Floresta Densa, a classe mais distinta em termos geomorfométricos foi a Floresta Densa Aluvial Dossel emergente.

Com base nas análises discriminantes foi possível se mapear a vegetação experimentalmente até o nível de subfisionomias. As subfisionomias das Formaçôes pioneiras e da Floresta
Densa foram discriminadas através das variáveis elevação e curvatura vertical.

Os dados derivados de SRTM não se mostraram promissores como insumos para o mapeamento da vegetação amazônica quando aplicados sob abordagem local e de maneira empírica, como feito neste estudo; recomenda-se que as análises sejam regionalizadas por feiçōes (formas básicas do terreno) e fundamentadas sobre conhecimentos de ecofisiologia da relação entre o relevo e a vegetação.

\section{AGRADECIMENTOS}

Os autores agradecem ao Prof. Dr. Pitágoras da Conceição Bispo (Unesp- Assis) pelo suporte durante as análises estatísticas.

\section{BIBLIOGRAFIA CITADA}

Castilho, C.V.; Magnusson, W. E.; Araújo, R. N. O.; Luizão, R. C.; Luizão, F. J.; Lima, A. P.; Higuchi, N. 2006. Variation in aboveground tree live biomass in a central Amazonian forest: effects of soil and topography. Forest Ecology and Management, 234(1-3): 85-96.

Chauvel, A.; Lucas, Y.; Boulet, R. 1987. On the genesis of the soil mantle of the region of Manaus, Central Amazonia, Brazil. Experientia, 43(2): 234-241.

Dargie, T.C.D. 1984. On the integrated interpretation of indirect site ordinations: A case study using semi-arid vegetation in Southeastern Spain. Plant Ecology, 55(1): 37-55.

Dargie, T.C.D. 1987. An ordination analysis of vegetation patterns on topoclimate gradients in South-East Spain. Journal of Biogeography, 14(3): 197-211.

Doornkamp, J.C; King, C.A.M. Numerical analysis in Geomorphology: An Introduction. London: Edward Arnold Ltd., 1971. 372pp.

Espírito-Santo, F.D.B; Shimabukuro; Y.E.; Kuplich, T.M. 2005. Mapping forest successional stages following deforestation in Brazilian Amazonia using multi-temporal Landsat images, International Journal of Remote Sensing, 26(3): 635-642.

Florinsky, I.V.; Kuryakova, G.A. 1996. Influence of topography on some vegetation cover properties. Catena, 27(2): 123-141.

Kahn, F.; Castro, A. 1985. The palm community in forest of Central Amazon, Brazil. Biotropica, 17(3): 210-216.

Kellndorfer, J.; Walker, W.; Pierce, L.; Dobson, C.; Fites, J.A.; Hunsaker, C.; Vona, J.; CLutter, M. 2004. Vegetation height estimation from Shuttle Radar Topography Mission and National Elevation Datasets. Remote Sensing of Environment, 93(3): 339-358.

Kirkby, M.; Atkinson, K.; Lockwood, J. G. 1990. Aspect vegetation cover and erosion on semi-arid hillslopes. In: Thomes, J. (Ed.). Vegetation and geomorphology. John Wiley, New York, p.25-39.

Kubota, Y.; Murata, H.; Kikuzawa, K. 2004. Effects of topographic heterogeneity on tree species richness and stand dynamics in a 
subtropical forest in Okinawa Island, southern Japan. Journal of Ecology, 92(2): 230-240.

Laurance, W.F.; Fearnside, P.M.; Laurance, S.G.; Delamonica, P.; Lovejoy, T.E.; Rankin-de-Merona, J.M.; Chambers, J.; Gascon, C.1999. Relationship between soils and Amazon forest biomass: a landscape-scale study. Forest Ecology and Management, 118(1-3): 127-138.

Lescure, J. P.; Boulet.1985. Relationships between soil and vegetation in a tropical rain forest in French Guiana. Biotropica, 17(2): 155-164.

Lieberman, M.; Lieberman, D.; Hartshorn, G.S.; Peralta, R. 1985. Small-scale altitudinal variation in lowland wet tropical forest vegetation. Journal of Ecology, 73(2): 505-516.

Lu, D. 2005. Integration of vegetation inventory data and Landsat TM image for vegetation classification in the western Brazilian Amazon. Forest Ecology and Management, 213(1-3): 369-383.

Lucas, R.M.; Honzak, M.; Curran, P.J., Foody, G.M.; Milne, R.; Brown, T.; Amaral, S. 2000. Mapping the regional extent of tropical forest regeneration in the Brazilian Legal Amazon using NOAA AVHRR data. International Journal of Remote Sensing, 21 (15): 2855-2881.

Manly, B.F.J. 1994. Multivariate statistical metods - a primer. New Zealand: Ed. Chapman and Hall, 210pp.

Ministério do Meio Ambiente - MMA. Projeto de Conservação e Utilização Sustentável da Diversidade Biológica Brasileira PROBIO, subprojeto Mapas de Cobertura Vegetal dos Biomas Brasileiros. Disponível em: <www.mma.gov.br/portalbio>. Acesso em: Jun. 2007.

Passos, M. M.1981. Variação fitossociologica dos cerrados em função da variação topográfica e de espaço. Dissertação de Mestrado em Geografia, Universidade de São Paulo/Faculdade de Filosofia, Letras e Ciências Humanas, São Paulo, São Paulo. 167pp.

Pelissier, P.; Dray, S.; Sabatier, D. 2001. Within-plot relatinships between tree species occorrences and hydrological soil constraints: na exemple in French Guiana investigated trough canonical correlation analysis. Plant Ecology, 162(2):143-156.

Pires, J.M.; Prance, G.T. 1985. The vegetation types of the Brazilian Amazonia. In: Prance, G. T.; Lovejoy, T. E. (Eds). Key environments: Amazonia. Pergamon Press, New York, p. 109-145.
RADAMBRASIL .1978. Levantamento dos Recursos Naturais. Folha SB-20 - Purus, Vol. 17, DNPM/Projeto RADAMBRASIL, Rio de Janeiro, Rio de Janeiro.

Schmidt, J.; Evans, I.S.; Brinkmann, J. 2003. Comparison of polynomial models for land surface curvature calculation. International Journal of Geographical Information Science, 17(8): 797-814.

Sollins, P.1988. Factors influencing species composition in tropical lowland rain forest: does soil matter? Ecology, 79 (1): 23-30.

Valeriano, M. M. 2003. Curvatura vertical de vertentes em microbacias pela análise de modelos digitais de elevação. Revista Brasileira de Engenharia Agricola e Ambiental, 7(3):539-546.

Valeriano, M.M; Carvalho Júnior, O. A. 2003. Geoprocessamento de modelos digitais de elevação para mapeamento da curvatura horizontal em microbacias. Revista Brasileira de Geomorfologia, 4(1): 17-29.

Valeriano, M.M. Modelo digital de variáveis morfométricas com dados SRTM para o território nacional: o projeto TOPODATA. 2005. In: Simpósio Brasileiro de Sensoriamento Remoto XII, Goiânia. Anais... São José dos Campos : INPE, 2005. p. 35953602.

Valeriano, M.M; Kuplich, T.M.; Storino, M.; Amaral, B.D.; Mendes, J.N.; Lima, D.J. 2006. Modeling small watersheds in Brazilian Amazônia with Shuttle Radar Topographic Mission - 90m data. Computers e Geosciences, 32(8): 1169-1181.

Velázquez-Rosas, N.; Meave, J.; Vázquez-Santana, S. 2002. Elevation variation of leaf traits in montane rain forest tree species at $\mathrm{La}$ Chinantla, Sourthen Mexico. Biotropica, 34(4): 534-546.

Veloso, H.P.; Rangel Filho, A.L.; Lima, J.C.A. 1991. Classificação da vegetação brasileira, adaptada a um sistema universal. IBGE, Rio de Janeiro.

Wittman, F.; Junk, W.J.; Piedade, M.T.F. 2004. The varzea forests in Amazônia: flooding and the highly dynamic geomorphology interact with natural forest sucession. Forest Ecology and Management, 196(2-3): 199-212.

Recebido em 01/10/2007

Aceito em 04/07/2008 